\title{
UNDERMINING PRIMA FACIE CONSENT IN THE CRIMINAL LAW
}

\author{
- Mark Dsouza - \\ *This is a version of the accepted manuscript. The final publication is available at \\ http://link.springer.com/article/10.1007/s10982-013-9188-z*
}

Even when a person (V) appears to have consented to another person (D) crossing a boundary set by her (V's) interests, we sometimes treat V's apparent consent as ineffective. This may either be because the law does not permit consent to validate the actions concerned, or because V's consent is undermined by the presence of additional factors which render it insufficiently autonomous to be effective. Although efforts have been made to categorise and systematically analyse the additional

factors in play in the latter set of cases, so far they have not yielded any measure of normative or doctrinal consonance. ${ }^{1}$

Broadly stated, the central theses of this paper are (1) that prima facie consent is undermined when the prima facie consenter's autonomy to choose whether or not to consent has been unfairly constrained, and (2) that theoretical and doctrinal clarity can be promoted by analysing the factors that unfairly constrain autonomy in the criminal law using a framework developed in contract law to determine analogous questions arising in relation to assent to a contract. In Part I, I describe the notion of consent that I use in this paper. This part of the paper is partly stipulative, but to the extent

1 See for instance Heidi M. Hurd, "The Moral Magic of Consent”, Legal Theory 2 (1996) 121 and Larry Alexander, “The Moral Magic of Consent (II)”, Legal Theory 2 (1996) 165. Hurd's proposal on this issue (which I examine in this paper) was unacceptable even to Larry Alexander, with whom she set out to co-author her paper. See also Rebecca Williams, "Deception, mistake and vitiation of the victim's consent”, Law Quarterly Review (2008) 132 for an overview of the doctrinal confusions (at least in English law) about the factors that vitiate prima facie consent. In fact, Arudra Burra, "The Significance of Consent”, available at http://www.law.ucla.edu/home/index.asp?page=817 (cited with permission) argues that it is futile to seek an overarching explanation for the manner in which prima facie consent is undermined, since different non-consensual acts are wrong for different, 'domain-specific', reasons. 
that I propose a non-orthodox view, it will be supported by normative arguments. In Part II, I defend the view that philosophically, valid consent negates the actus reus of a criminal offence, whereas acting on the basis of putative consent negates the mens rea of the offence. In Part III, I critique Heidi Hurd's proposed framework for the criminal law's analysis of the factors that undermine prima facie consent, ${ }^{2}$ and describe the analytical model for examining the validity of consent in the criminal law that flows from the notions of consent described and defended in Parts I and II. Finally, in Part IV, I argue that this model relies on notions of unfair constraint of autonomy that can usefully be analysed using a framework borrowed from contract law consent scholarship.

This is primarily a normative study of the factors that vitiate prima facie consent, and although the importance of consent transcends the civil-criminal divide in law, in this paper I focus primarily on issues arising in liberal criminal law. Although I borrow examples mainly from English criminal law, I am not setting out to describe or defend the doctrinal law of any jurisdiction.

\section{A Baseline Understanding of Consent}

Although consent is one of the most important situational variables that the law confronts, there has been little unanimity amongst theorists on the answers to many core questions about the ontology and functioning of consent. To some extent at least, this is because the word 'consent' is used by academicians and judges to refer to a collection of connected, but non-identical ideas and phenomena. As a result, even a foundational question like, "What is consent?" has plausibly been answered in several different ways, each shedding some light on a different characteristic of the concept. This has led some theorists to abandon that question altogether, and focus instead on a different, logically subsequent, question: "How does consent achieve what it does?"3 The advantages of this approach are obvious: it allows one to identify and describe the features of consent that make it important in the real, as opposed to the philosophical, world. Using their

2 See Hurd, 'Moral Magic', 138-145.

3 Alan Wertheimer, "What is Consent? And is it Important?", Buffalo Criminal Law Review 3 (2000) 557. 
findings, these theorists inductively reason about the nature of consent, and suggest answers to vexed problems of law. Unfortunately, since there are also a variety of plausible opinions about what consent does, ${ }^{4}$ any answer to the question "How does consent achieve what it does?" that focusses on only one type of case gives us only a partial picture, unsuitable by itself for inductive hypothesising about consent. Therefore, instead of adopting either of these approaches, I ask a question logically prior even to the question of what consent is - "What is it to have the ability to give valid consent?" Beyleveld and Brownsword have, in their meticulous study of the Hohfeldian nature of consent, addressed this question, ${ }^{5}$ and I will adapt their findings to flesh out the view of consent that I adopt in this essay.

\section{I.1 The Hohfeldian identity of the ability to validly consent}

The ability to grant valid consent exists in jural relation to the actual phenomenon of consent. A good starting point for our inquiry then is to identify the type of jural relation concerned. Beyleveld and Brownsword argue that in consenting, a person either exercises a power to change the baseline relationship between the parties to the consenting transaction, or authors a change internal to this baseline relationship. ${ }^{6}$ The appropriate characterisation in a given case depends on how the baseline relationship between the consenting parties is described. For instance, where the baseline relationship between the consenter, $\mathrm{V}$ and another person, $\mathrm{D}$ is one of right and duty, the relationship may be described in one of two ways:

4 Peter Westen proposes that consent, insofar as it is relevant to the criminal law or tort law, creates a Hohfeldian privilege, although in other contexts it may create a right or power. For Hurd, it creates rights and obligations in others. Beyleveld and Brownsword say that depending on the terms used in consenting, consent creates either a right, privilege, power or immunity, or permutations and combinations thereof. See Peter Westen, "Some Common Confusions About Consent in Rape Cases”, Ohio State Journal of Criminal Law 2 (2004) 334; Hurd, 'Moral Magic', 124; and Deryck Beyleveld and Roger Brownsword, Consent in the Law (Oxford: Hart Publishing, 2007), 64-85.

5 Beyleveld and Brownsword, Consent, 64-85.

$6 \quad I d$. 
1. $\mathrm{V}$ has a right that $\mathrm{D}$ do an act, $\alpha$, and $\mathrm{D}$ has a duty to $\mathrm{V}$ to $\alpha$. Additionally, Vhas the power to consent to D not aing, and V has a liability to D's exercise of this power; or

2. $\mathrm{V}$ has a right that $\mathrm{D} \alpha$ unless $V$ consents to $D$ not $\alpha i n g$, and $\mathrm{D}$ has a duty to $\mathrm{V}$ to $\alpha$ unless $V$ consents to D not aing.

For Beyleveld and Brownsword, the appropriate description of the baseline relationship depends on the context. Where the first description is appropriate, to consent is to exercise a power (which exists in addition to the right-duty relationship), and where the second description is appropriate, to consent is to effect a change internal to the right-duty relationship. They make similar findings in relation to alternate cases in which the baseline relationships between $\mathrm{V}$ and $\mathrm{D}$ are either privilege and no-right; power and liability; or immunity and disability.

Although the appropriate description of the baseline relationships between $\mathrm{V}$ and $\mathrm{D}$ may depend on the context of the relationship, the Hohfeldian nature of the ability to validly consent remains the same - it is always a power. The appropriate description of the baseline relationship changes only whether the power is external to the baseline relationship, or an integral part of it. As a useful shorthand then, I will take the ability to validly consent to be a Hohfeldian power. By consenting, $\mathrm{V}$ alters the jural relations between herself and $\mathrm{D} .^{7}$

\section{I.2 Granting consent}

If the ability to validly consent is a power, then the necessary conditions for its exercise are to be found in the necessary conditions, if any, for the exercise of a power. For Hohfeld, when a given legal relation changes due to some superadded fact or group of facts which are under the volitional control of a human being, the person whose volitional control is paramount is said to possess the

7 See also in this connection note 4, supra. For the purposes of this study, I need not adopt a strong stance on the identity of the jural relations altered or created. It suffices for me to say that the exercise of the power to consent alters some jural relations of the consenter with others, in a context-specific way. 
power to effect that change. ${ }^{8}$ This suggests that in Hohfeld's view at least, the exercise of power involves an exercise of volition - the active making of a choice. This is a widely accepted view, ${ }^{9}$ and it is the view that I adopt here.

As with any choice, in order for the chooser to truly have authorship over the choice, the choice must be hers, and not forced upon her by someone else. This connects with Hurd's and Alexander's identification of consent's 'moral magic' as flowing from its being an exercise of autonomy. ${ }^{10}$ Accordingly, for consent to be morally (and to the extent that the law follows morals,

8 Wesley Newcomb Hohfeld, Fundamental Legal Conceptions (New Haven: Yale University Press, 1919), 50-51.

9 See for instance Hurd, 'Moral Magic', 126; Alexander, 'Moral Magic (II)', 166; and Kimberly Kessler Ferzan, “Clarifying Consent: Peter Westen's The Logic of Consent", Law and Philosophy 25 (2006) 193, 206, each of whom argue that consent is a mental state of choice or authorisation rather than mere desire.

Peter Westen, The logic of consent: The diversity and deceptiveness of consent as a defense to criminal conduct (Aldershot: Ashgate Publishing Limited, 2004), 28-34 seems to disagree. However on closer examination, the disagreement disappears. Since Westen understands mental states of desire as being the product of choice, he too accepts the volitional basis of consent; and Westen's assumption that Alexander necessarily requires one to be aware of one's entitlement to withhold consent in order to give valid consent is probably wrong. Alexander's assertion that V consents when she forgoes her moral objection to D's boundary crossing ('Moral Magic (II)', 166) was made in response to Hurd's affirmation that for $\mathrm{V}$ to consent she must positively invite, rather than merely be indifferent to, D's boundary crossing ('Moral Magic', 130-131). He did not need to take, and should not be read as having taken, the firm position that $\mathrm{V}$ must be aware of her moral objection to D's boundary crossing in order to forgo it. In fact Alexander and Westen are agreed that indifference can amount to consent, and Alexander's argument against Hurd would stand even if he substituted the words 'forgo one's moral objections, to the extent that, as a matter of law (whether or not one is aware of it), one has any' for the words he actually uses, viz. 'forgo one's moral objections', but of course, such a cumbersome qualifier was superfluous to the argument being made. Nevertheless Westen's point about being able to consent without being aware of one's legal power to consent stands, and a more technically correct stipulation of the act of consenting would be choosing to forgo one's moral objections, to the extent that, as a matter or law (whether or not one is aware of it), one has any.

10 Hurd, 'Moral Magic', 124; Alexander, 'Moral Magic (II)', 165. 
legally) transformative, the choice made while exercising the power to consent needs to have been made with a sufficient amount of autonomy to morally attribute it to the chooser.

Because nothing of significance to this paper turns on them, I will not express any opinion on the various other disputed questions that arise in relation to the granting of consent. Specifically, I will not address questions relating to whether consent necessarily requires that the consenter invite the boundary crossing, and whether purely a subjective state of mind can create effective consent.

\section{Consent and the Elements of an Offence}

We begin by considering how actual and putative consent works in the criminal law. Most theorists agree that the presence or absence of actual or putative consent makes a difference either to whether the actus reus of an offence has occurred, or whether the defendant caused it with the requisite mens rea, or perhaps, both. However, there remains considerable dispute as to the specifics, and as to whether consent performs different structural functions in the context of different offences. I will consider the main questions arising in the context of actual and putative consent separately and propose my own working conclusions.

\section{II.1 Actual Consent}

If the individual's autonomy is fundamental to liberalism, and an individual's autonomy over her interests entitles her to consent to another's crossing of a boundary set by these interests, then actual consent, ${ }^{11}$ given prior to, or contemporaneously with, the impugned action, negates the occurrence of a 'qualifying harm' meriting state attention. Translated into criminal law terms, this means that prior or contemporaneous actual consent negates the actus reus of the offence, instead of providing a supervening defence to criminal liability. ${ }^{12}$ In a liberal state, actus reus stipulations for harm-

11 By the term 'actual consent' I mean consent that is legally transformative.

12 Contrary views exist. Fletcher argues that, at least in the context of rape, consent functions as a defence. George P. 
predicated offences ${ }^{13}$ are either implicitly or explicitly premised on the absence of consent, and when there is consent, this premise falls, and the actus reus of the offence is not performed.

This assertion is far from uncontroversial, and yet discussion on the issue has often missed the point being made, especially in the context of rape, where the sensitive nature of the offence sometimes appears to skew the argument. George Fletcher for instance argues that V's non-consent is not an element of the offence of rape, but rather, her actual consent is a defence. ${ }^{14}$ For him, when D commits the presumptive wrong of sexual penetration, he ${ }^{15}$ may be called to answer for his actions to the polity, but consent functions "as a ground for regarding the sexual act as a shared expression of love rather than as an invasion of bodily integrity". Antony Duff argues that Fletcher's stance is implausible. He concedes that a general prohibition on sexual penetration is coherent, but says that "it makes no moral sense to citizens of contemporary liberal democracies: we should not have to answer, to our fellow citizens through the criminal courts, for every act of sexual penetration". ${ }^{16}$ For him therefore, 'absence of consent' is an element that must be 'present' to

detail slightly later. Beyleveld and Brownsword take a stance that appears to be more generalised. They assert that, “[i]n practical discourse, whether ethical (moral) or legal, consent functions as a justificatory reason." Beyleveld and Brownsword, Consent, 59. They analyse consent as what they call a 'procedural justification' and use Hohfeldian analysis to study how consent functions in legal relationships. While their Hohfeldian analysis is extremely valuable, their situation of consent in the realm of justificatory reasons is confusing, at least within a liberal state, in which individual autonomy is privileged.

13 Or indeed offence-predicated offences. In the rest of this paper, my references to harm-predicated offences should be understood as also including offence-predicated offences.

14 Fletcher, Rethinking, 706, 552-579, 683-754. See also Michelle M. Dempsey and Jonathan Herring, "Why Sexual Penetration Requires Justification”, Oxford Journal of Legal Studies 27(3) (2007) 467.

15 I use the male gender when referring to the defendant in a potential rape case simply because in many countries the laws are such that only males can be guilty of rape. I make no comment on the appropriateness of such a stipulation.

16 R. A. Duff, Answering For Crime (Oxford: Hart Publishing, 2007), 209. 
transform the legal act of sexual intercourse into rape. ${ }^{17}$ My reading of the argument is that both Fletcher and Duff make some valid points, but both also make invalid conclusions. I think Fletcher is right insofar as he can be read (or arguably read down) as saying that in all cases of sexual penetration, some explanation can be called for. Certainly no person is entitled to sexually penetrate another person (or for that matter, cross any of her other boundaries) at will. In my view, it is the characterisation of sexual penetration as a 'presumptive wrong' that muddies the waters.

At its root, the disagreement between Fletcher and Duff is on the sense in which they understand the unqualified term 'sexual penetration'. For Fletcher it is presumptively nonconsensual, and therefore consent is a defence. For Duff, it seems to be presumptively consensual, and therefore it is anti-liberal to demand that all persons engaging in sexual penetration should answer to the polity, through the criminal courts, for every act of sexual penetration. If my reading of Duff is correct, then both sides are wrong: the mere statement that D sexually penetrated V does not reveal anything about V's attitude towards the sexual penetration. In other words, the act description 'sexual penetration' is neutral as to consent. Sexual penetration with consent does not violate the autonomy of the person consenting to the penetration, and so it is not a qualifying harm. On the other hand, sexual penetration without consent is certainly a presumptive wrong.

Analytically therefore, in a liberal state, there are two stages of inquiry before an act is identified as a presumptive wrong, for the commission of which the actor may be called upon to answer to her fellow citizens in a criminal court. We know that a perfectly liberal state can legitimately ask a subject to explain her actions only if they have an effect on the interests of another, and so instances of pure self-harm (or indeed self-help), are nobody else's business. ${ }^{18}$

17 Id. at 208-210.

18 Non-harm predicated offences would not exist in such a state. In the real world, there exist several offences that are explicable at least partly by reference to paternalistic or welfare-state principles. These include social protection offences, tax offences and inchoate offences. The discussion here does not apply to non-harm predicated offences. 
Therefore $\mathrm{V}$ has an 'in-principle' moral complaint against D only if D's actions affect V. This is not to suggest that every action that has an effect on the interests of others is a presumptive wrong, or that there is any general prohibition on acting in such a manner. Liberal respect for autonomy is compatible with allowing a person to consent to boundary crossings, and so even where $\mathrm{V}$ has an in-principle moral complaint, there is no qualifying harm if she validly consents. The initial stage of inquiry is therefore restricted to establishing the in-principle moral complaint. Thereafter, a second level of inquiry must determine whether, if consent could in principle have legalised the boundary crossing, there was valid consent. ${ }^{19}$ It is only after the impossibility or absence of valid consent to an action grounding an in-principle moral complaint is established, that the action concerned becomes a qualifying harm or a presumptive wrong, and only at this stage can a liberal state require a citizen to answer to her fellow citizens, through the criminal court, for her action.

If my analysis is correct, then there is no structural difference between rape and any other offence involving harm to another's interests (and to which consent is a 'defence'). ${ }^{20}$ The distinction is only that in the definition of rape and other sexual offences, the generally implicit requirement of the absence of consent for the actus reus of an offence, is made explicit.

This approach to prior actual consent also means that once V consents, D's attitude towards the consent is irrelevant to the commission of the actus reus. As a matter of fact, D cannot commit the actus reus of a harm-predicated offence, even when she acts without knowledge of V's consent, or acts in the hope that $\mathrm{V}$ was not consenting. At most, it might be possible to argue that in such

19 The term 'inquiry' is something of a misnomer in this context. I have in mind not an inquiry by a criminal court or the polity in any other form. For me, the presence or absence of consent is primarily a matter of self-assessment by the person whose interests are affected.

20 I use the term 'defence' colloquially here. Unless otherwise specified, for the rest of this piece I will be confining my comments to harm and offence predicated offences to which consent is, in the loose sense, a defence. 
cases D attracts attempts liability. ${ }^{21}$

\section{II.2 Putative Consent}

Where $\mathrm{D}$ acts on the basis of an incorrect belief that $\mathrm{V}$ has consented, the qualifying harm, or presumptive wrong, has occurred. This usually coincides with the satisfaction of the actus reus requirements of an offence stipulation. Consider the offence of rape. The actus reus of rape expressly stipulates that consent must be absent, and where D has intercourse with V incorrectly believing that she has consented, the actus reus of rape undoubtedly occurs. V's apparent consent in such a case may be characterised as putative consent.

D commits the prima facie offence of rape when he authors the actus reus elements with the mens rea required in respect of each of them. Where $\mathrm{D}$ believes that $\mathrm{V}$ consents to intercourse, he does not possess the requisite mens rea with regard to the absence of V's consent. ${ }^{22}$ He therefore does not possess the necessary mens rea to commit rape, and need not offer a supervening defence.

In some ways, rape, with its express stipulation as to the absence of consent, is the easy case for analysing prior putative consent. Most offence stipulations do not expressly require the absence of consent as an element of the actus reus. Nevertheless, if I am right in saying that a liberal criminal system always incorporates at least an implicit 'absence of consent' actus reus stipulation for harm-predicated offences, then it follows that even for offences without an express 'absence of consent' stipulation, D's successful claim that she acted in the mistaken belief that $\mathrm{V}$ was consenting negates a mens rea element required for the offence. This approach to analysing the role of consent

21 Pace Wertheimer who does not seem to consider this possibility. Wertheimer, 'What is Consent?', 571. Of course, other issues such as whether legal impossibility precludes attempts liability will also arise, and I do not wish to enter into those debates in this paper.

22 I stress that this is not an assertion as to the posited law in any particular criminal legal system. In the United Kingdom for instance, the belief as to the victim's consent must be reasonable for the defendant to disprove mens rea. The assertion made in the main text is an in-principle argument, and should be read as such. 
in offence definitions simplifies the analysis considerably, and in my view, does so correctly.

One consequence of adopting this analytical approach is that it may, depending on one's attitude to more general issues of criminal defences, support the argument that an unreasonable mistake as to V's consent should exonerate D completely. I personally do not think that this is a problem, although Fletcher would no doubt think this to be incorrect. ${ }^{23}$ Nevertheless for this piece, I need not take a position on this issue. Either view is reconcilable with the argument I am building.

\section{Undermining consent}

With this understanding of how real and putative consent affects the legal assessment of whether a crime has occurred, we can now examine questions relating to the validity and efficaciousness of consent. Under what circumstances is V's apparent consent so tainted as to be either non-existent, or ineffective? And on what philosophical basis? Much of the writing on this subject has been intuition driven, and because their intuitions regularly pull writers in different directions, disputes remain. However, at a more general level, most theorists tend to agree that there are certain factors, the presence of which nullifies consent, such that the apparent consent to an action is not legally transformative. Implicit in this assertion is the proposition that even if it is shown that $\mathrm{V}$ chose to permit a boundary crossing, this does not conclude the question of whether there was effective consent. Hurd develops this point in an interesting direction by defining 'prima facie consent' as the possession of the subjective mental state of consent (which she calls the 'mens rea of consent') along with (if necessary) an external manifestation of the consent (which she calls the 'actus reus of consent'). She then argues that when an agent grants prima facie consent "under circumstances analogous to those in which a [theoretical] defendant is accorded an excuse, her [grant of prima facie consent] should be deemed insufficient to vitiate the wrongfulness of the [actual] defendant's conduct". ${ }^{24}$ She explains that in the same manner that a theoretical defendant is excused "if he lacks

23 Fletcher, Rethinking, 699-707.

24 Hurd, 'Moral Magic', 139. 
(1) the capacity or (2) the opportunity for meaningful choice", a putative consenter who lacks the capacity or opportunity for meaningful choice in consenting fails to give valid consent. ${ }^{25}$

Hurd describes her approach to dealing with the factors that undermine consent as her 'second identity thesis', viz. that there is symmetry between the ways in which criminal or tortious liability is defeasible despite the fulfilment of the requirements of the prima facie offence, and the ways in which consent is defeasible despite it having prima facie been accorded. She expressly caveats that her second identity thesis is only a tentative proposal, and that the question is a complicated one. Nevertheless she claims that "there is considerable plausibility to the claim that the conditions of criminal responsibility are identical to the conditions under which a person should be deemed sufficiently autonomous to exercise the moral magic of consent". ${ }^{26}$

Hurd's argument rests entirely on analogy and intuition - she states her hypothesis, and relies on the intuitive appeal of the analogy to substitute an explanation for why it is correct. But although analogies are good tools to illustrate an argument, they are poor at making the argument. There is no philosophical basis to say that consent - which is an instance of the exercise of autonomy, mirrors criminal responsibility - which depends on several factors in addition to the capacity to exercise of autonomy. Moreover, Hurd's own cursory attempts at fleshing out the system of consent generated by the second identity thesis ${ }^{27}$ raise intuitive doubts about its plausibility. Even Larry Alexander, with whom she set out to write her paper, rejects the second identity thesis and presents a radically different model to deal with the (more limited) question of how coercion defeats consent. Alexander points out that there is no wrong in consenting that needs to be excused, and that therefore there is no way to calibrate the level of threat required to vitiate consent with the different acts to which one might consent, in the manner that one might compare the level of threat required

$25 \mathrm{Id}$. at 140.

$26 I d$. at 144 .

27 Id. at 140-145. 
to excuse coerced actions amounting to a prima facie offence. Furthermore, he points out that while excuses come in degrees, it is strange to think of degrees of consent. ${ }^{28}$ As a result, although Alexander believes that even trivial threats must necessarily nullify consent, ${ }^{29}$ Hurd says that it is a complicated question to which she has no conclusive answer, but accepts that there are conflicting intuitions as to the degree of coercion required to nullify consent. ${ }^{30}$

In rejecting Hurd's second identity thesis, Alexander proposes a model that works very differently to anything that Hurd suggests, and which explains how the background considerations motivating putative consent are relevant to determining whether such consent is undermined by coercion. Where Hurd suggests that the background motivations that defeat consent run parallel to the conditions that excuse criminal conduct, Alexander addresses these motivations directly, rather than by analogy. In his model, “[o]ne consents to an act when, acting with the capacity necessary for autonomous, responsible agency, one chooses to forgo valid rights-based moral objections to the act... and to the alternative presented by the actor that motivates the choice to forgo such objections." ${ }^{31}$ He rightly recognises that on his model, a person who consents to sexual intercourse would be found to have been raped if she consented because of the threat of a pinch, and argues that therefore "[n]ot all nonconsensual sex should be regarded as a serious crime". ${ }^{32}$ Perhaps this is an unnecessary concession to have made. It strikes me that in most cases, a jury simply will not believe that a person was coerced into having sex against her will because she was threatened with a pinch. But even if they did, and it was found that consent was vitiated, a defendant might credibly claim lack of mens rea on the basis that he didn't believe that the victim's consent to sex was caused by the threat of a mere pinch, and therefore, he acted on the basis of putative consent. In the unlikely event

28 Alexander, 'Moral Magic (II)', 172.

$29 \mathrm{Id}$. at 173.

30 Hurd, 'Moral Magic', 143-144.

31 Alexander, 'Moral Magic (II)', 172.

32 Id. at 173 . 
that the jury believes that consent was vitiated, and that the defendant knew it was, then there seems to be no reason to treat this instance of non-consensual sex any less seriously than one would treat any other instance of non-consensual sex. That apart, Alexander's model seems to be far more intuitively appealing than Hurd's more general proposal.

However, Alexander's model addresses only the special case of coercion - it does not claim to compete with Hurd's proposal in terms of scope, and does not set out a general framework to explain the manner in which apparent consent is undermined. Thus it provides no guidance as to instances in which putative consent is induced inappropriately, by means such as fraud and undue influence. Perhaps, as Burra suggests, it is futile to look for such an overarching explanation for the manner in which prima facie consent is undermined, since the reasons for which different nonconsensual acts are wrong are different, and 'domain-specific'. ${ }^{33}$ However, Burra's insight that no single rule can exhaustively explain all situations in which consent is undermined, does not necessarily rule out the existence of a framework for approaching the question. It may just be that within the same framework, different standards apply in different domains.

It would be useful to reconsider this possibility after drawing out the implications of the proposals made in this paper for the undermining of consent. The two stage inquiry proposed in $\S I I .1$ for when an act amounts to a presumptive wrong suggests that D commits a presumptive wrong when (1) she crosses a boundary set by V's entitlement (let's call it 'X'), and (2) V does not consent to this crossing. We can unpack the second stage test in terms of the explanation of consent proposed in $§$ I.2. Accordingly, $\mathrm{V}$ does not consent when she does not exercise her power to consent, or when she is insufficiently autonomous in exercising it. We see now that although a presumptive wrong may be committed when D usurps V's power to grant or withhold consent in respect of $\mathrm{X}$, ${ }^{34}$

\footnotetext{
33 Burra, 'Significance', 11.
}

34 I use the term 'usurp' in a more morally loaded sense than 'boundary crossing'. D usurps V's power to consent in respect of entitlement $\mathrm{X}$ when $\mathrm{D}$ snatches and exercises that power instead of V. D crosses a boundary set by $\mathrm{X}$ both 
this is not a necessary condition for the commission of a presumptive wrong. The presumptive wrong may also, for instance, be committed when $\mathrm{D}$ forces $\mathrm{V}$ to exercise her power to consent to the boundary crossing. In such a case, although D does not usurp V's power to grant or withhold consent in respect of X, she does usurp V's autonomy over how to exercise her power over X.

This last point will become clearer as the argument unfolds, but if it is correct, it suggests that V's apparent consent ${ }^{35}$ is vitiated either when she does not actually exercise the power to consent in respect of $\mathrm{X}$ in the manner that $\mathrm{D}$ treats it as having been exercised, or when her autonomy over how she exercises her power to consent in respect of $\mathrm{X}$ is usurped. We can treat these cases separately, as they negate putative consent in different ways.

\section{III.1 Non-exercise of power to consent}

Even where V appears to have granted consent, her seemingly valid exercise of autonomy may be illusory. For instance, an apparent grant of consent may be null and void if V lacks the capacity to exercise the autonomy necessary to grant consent. A person lacks the capacity to make autonomous decisions, and by extension to consent, if she is not a morally responsible agent at the time that she is called upon, or purports, to consent. Conditions of infancy, insanity and automatism defeat a person's status as a responsible agent, and a person cannot, while in the thrall of any of these conditions, exercise the moral autonomy necessary to give genuine consent. ${ }^{36}$ No matter what $\mathrm{V}$ does, says, or even subjectively decides while sleepwalking, her apparent consent is never real, and although D may be able to raise an absence of mens rea defence based on V's putative consent, she

when D usurps V's power to consent in respect of X, and when D deals with X within the scope of V's consent.

35 I exclude from this analysis cases in which $\mathrm{V}$ was not given the chance to exercise her power to consent at all - for instance in purse-snatching cases. In such cases, there is not even apparent consent.

36 The standards applicable to determine when an agent is too young, or mentally incapacitated, or devoid of deliberative control, or indeed as will be discussed presently, too intoxicated to exercise her autonomy will depend on the context. For instance, a person may be too young to consent to sex, but may be old enough to consent to medical treatment or the risks inherent in an organised sport. 
cannot negate the actus reus based on the presence of consent. V may of course ratify D's action upon subsequently becoming a responsible agent, but a subsequent ratification is neither philosophically nor functionally equivalent to consenting to it at the time. ${ }^{37}$

The same analysis also applies to a person who is too intoxicated to access her rational capabilities. I caveat however, that one need not be in peak decision-making form in order to be morally autonomous, and where intoxication merely disinhibits $\mathrm{V}$, or otherwise affects the efficiency of her autonomous decision-making capacities, $\mathrm{V}$ remains morally autonomous ${ }^{38}$ and capable of disposing of her interests as she pleases. Her exercise of autonomy, even if performed under these circumstances, is a phenomenological fact, the existence of which cannot be denied.

A far more complex set of cases arise when V's prima facie grant of consent is implicitly or explicitly premised on beliefs that turn out to be false, or expectations that do not materialise. To demonstrate that, consider the following scenarios:

(a) $\mathrm{V}$ chooses to consent to conduct which amounts to $\alpha$, but which she perceives to be something other than $\alpha$.

37 I cannot defend this assertion in this paper. Briefly however, my view is that if consent is the autonomous exercise of the power to permit a boundary crossing, then ratification, coming as it does after the crossing commences or concludes, does not permit the interference - it waives (to the extent possible) the accrued complaint arising from it.

38 See in this connection the difficult, but correctly decided case of $R$ v. Kingston [1994] 3 WLR 519, in which T, knowing that D had paedophilic tendencies but had hitherto always resisted them, surreptitiously drugged D in order to disinhibit him, and put him in a room with a drugged naked boy. Because of the effects of the intoxication, D gave into temptation, and $\mathrm{T}$ filmed $\mathrm{D}$ in order to blackmail him. D was held responsible for his actions despite the disinhibiting effect of the involuntary intoxication, and was convicted of an indecent assault on a youth. As Burra, 'Significance', 11, cautions though, the boundary between mere disinhibition and loss of capacity to consent is domain-specific - a person who is too intoxicated to have the capacity to consent to sex, may still be able to permit someone to use her bathroom. In making the general assertion that mere disinhibition does not deprive a person of the capacity to consent, I do not imply that the same evaluative standard of intoxication is relevant in all contexts. 
(b) $\mathrm{V}$ chooses to consent to conduct $\alpha$ on the condition that circumstance $\beta$ exists or will exist before or during $\alpha . \beta$ does not exist before or during $\alpha$.

(c) $\mathrm{V}$ chooses to consent to conduct $\alpha$, or an act that amounts to $\alpha$, in the expectation that consequence $\gamma$ will arise. She may also frame her consent as consent to $\gamma$, where for $\gamma$ to happen, she realises that it is necessary (but not sufficient) that $\mathrm{D}$ does $\alpha . \gamma$ does not happen.

Complex actus reus stipulations in offence definitions are sometimes divided for analytical convenience into conduct, circumstance and consequence elements. The three scenarios described above relate to false beliefs as to the nature of the conduct $(\alpha)$, the existence of circumstances $(\beta)$ at the time of $\alpha$, and belied expectations $(\gamma)$ as to the consequences of $\alpha$.

Take scenario (c) first. The English case of Linekar ${ }^{39}$ is an example of this sort of case. Here a prostitute consented to sex with the defendant on the understanding that the defendant would pay her later. Despite the fact that he did not later pay, the court held that the prostitute had not been raped. Hurd examines a slightly different example of the same sort of case, and argues for a similar outcome. Her example involves V, who consents to 'impregnation' by D. She argues for the rejection of this sort of description of the scope of V's consents because it is 'causally complex' - it includes within itself the description of the consequences that must flow from the conduct in which D must engage. If we referred to V's causally complex description of the scope of her consent, then if V did not become pregnant after intercourse with $\mathrm{D}$, the intercourse would have been non-consensual even though D had had no control over the factors due to which the desired consequence failed to materialise, and even though at the time of the intercourse, $\mathrm{V}$ was willing $\mathrm{D}$ to do exactly what he was doing. ${ }^{40}$ The intuition behind the Linekar decision and Hurd's preferred outcome in her example is the same - when V expressly or implicitly consents to $\alpha$ in the expectation of $\gamma$, the failure of $\gamma$ to materialise should not imply that $\mathrm{V}$ did not consent to $\alpha$. This makes logical sense. If

39 R v. Linekar [1995] QB 250.

40 Hurd, 'Moral Magic', 133. 
$\mathrm{V}$ expects $\gamma$ to occur only consequent to $\alpha$, then even for $\mathrm{V}, \gamma$ is not a precondition for her consent to $\alpha$. In other words, the creation of legally valid consent to $\alpha$ is not contingent on the happening of $\gamma$, since $\gamma$ will happen only after $\alpha$. Moreover, consent cannot be retrospectively created or nullified depending on whether or not certain expected consequences materialise. Fundamental principles of criminal law bar the retrospective criminalisation of actions that were not wrong when performed. If $\gamma$ does not happen, then $\mathrm{V}$ is aggrieved, if at all, by the non-occurrence of $\gamma$, and not by the occurrence of $\alpha$.

So V cannot, in the exercise of her autonomy, condition her consent to D's conduct on that conduct giving rise to specified consequences, either explicitly, or by using a causally complex act description. Can she instead condition her consent on D's conduct answering to her own description of it, or on the prior or contemporaneous existence of certain circumstances? Consider a case of the nature of scenario (a) above. In Williams, ${ }^{41} \mathrm{~V}$ believed that D's penetration of her vagina with his penis was a medical procedure to improve her singing voice, rather than sex, and consented accordingly. Here V's description of the conduct being performed was different from what happened. Unsurprisingly D was convicted of rape. Clearly, if V has a false belief as to the nature of the conduct to which she appears to consent, she does not actually consent to the conduct performed. This follows from principle as well - if, in the exercise of her autonomy, V can choose when to allow a boundary crossing, she can also choose what type of boundary crossing she permits. When she misapprehends the nature of what she permits, she does not actually permit it. ${ }^{42}$

$41 R v$. Williams [1923] $1 \mathrm{~KB}$ 340. See also $R$ v. Flattery (1877) 2 QBD 410, where V believed that she was undergoing a surgical procedure to cure her fits, rather than sexual intercourse. Here too, D was convicted.

42 This analysis also explains the principled foundation of the decisions in $R v$. Konzani [2005] EWCA Crim 706 and $R$ v. Dica [2004] EWCA Crim 1103. When V consents to sexual intercourse, she does not also thereby consent to a boundary crossing of a wholly different nature, by which $\mathrm{D}$ deliberately puts $\mathrm{V}$ at an unusual risk of infection. So although $\mathrm{D}$ does not rape $\mathrm{V}-\mathrm{V}$ 's consent to the intercourse remains effective - if $\mathrm{V}$ contracts HIV, D inflicts grievous bodily harm upon her and cannot raise a consent based defence. 
On the same logic, she can also impose conditions as to the circumstances under which she permits a boundary crossing. Consider an example that conforms to scenario (b). In Assange, ${ }^{43} \mathrm{~V}$ consented to sex with D only if he wore a condom. D had sex with V, but did not wear a condom. The court rightly ruled that under English law, he had committed rape. It is important to distinguish circumstances - which do or do not exist prior to or contemporaneously with the conduct concerned - from consequences, which, by definition, come into existence subsequently. $\mathrm{V}$ can, in the exercise of her autonomy, choose to make the existence of specified circumstances a precondition for consent, but cannot make subsequent consequences a precondition for consent. Of course $\mathrm{V}$ can, to some extent, rephrase her expectations as to consequences in terms of circumstances. For instance, had the prostitute in Linekar granted consent on the precondition that D was, and at all relevant times remained, ready, willing and able to pay the agreed charge, then because this precondition was not met (as a matter of fact, D had no money and never intended to pay) her consent would never have arisen. It would have been legitimate for the court to convict D on those altered facts. However, even this restatement of the terms of V's consent would not secure a conviction if, after sex, D had changed his mind and decided not to pay. Hence the restatement too does not allow consent to be conditional upon expected consequences. Moreover, to engineer even this (limited) repackaging of expected consequences into present circumstances, V must exercise her volition by actively choosing to do so. ${ }^{44}$ This flows from the fact that the power to grant consent is a volitional act of choosing rather than the passive mental state of desiring. Therefore, if $\mathrm{V}$ had never considered rephrasing her expected consequences in terms of circumstances, then the restated circumstances

43 Assange v. Swedish Prosecution Authority [2011] EWHC 2849 (Admin).

44 This also means that by such a volitional act V can make her consent conditional upon factors that are morally unattractive. Thus she may consent only if $\mathrm{D}$ is rich, or Jewish, or plans to marry her. I think that $\mathrm{V}$ is entitled to do so; indeed that is the essence having autonomy over one's entitlements. There is no good reason to ignore V's autonomous stipulation of the terms of her consent. If these conditions are not met but D is unaware of them, he may raise a mens rea based defence, but otherwise, D does commit a prima facie offence by crossing V's boundary. 
would not be preconditions for her consent. The same applies also to circumstances that V does not consider at all, but which are such that, had she known of their existence, she would not have consented. Hence V cannot nullify her consent to sex by saying, "Had I known that D had AIDS, I would not have consented". ${ }^{45}$ This scenario is different from one in which D deceives V as to his (D's) HIV status (or indeed any other circumstance), and this deception is causative. In such a case, if, and to the extent that, $\mathrm{V}$ actively (though not necessarily explicitly) relies on D's representation, her consent is contingent upon the existence of the circumstance described by D. Its non-existence renders V's consent stillborn. ${ }^{46}$

In summary then, even where $\mathrm{V}$ appears to have consented to some conduct $\alpha$, she will not actually have exercised the power to grant such consent if she was under some incapacity, or if her consent was premised on a false belief as to the nature of conduct $\alpha$, or if it was, by an active (though not necessarily explicit) choice, made conditional upon the truth of what turned out to be a false belief as to the prior or contemporaneous existence of certain circumstances $\beta$.

\section{III.2 Usurpation of autonomy over the power to consent}

If $\mathrm{V}$ does exercise her power to consent by choosing to permit $\mathrm{D}$ to cross a boundary set by her primary entitlement $X$ (the 'primary boundary crossing'), she can prima facie be said to consent. ${ }^{47}$

45 See $R$ v. $B$ [2006] EWCA Crim 2945; $R$ v. Konzani [2005] EWCA Crim 706; $R$ v. Dica [2004] EWCA Crim 1103.

46 The same principle explains the common law rule that a causative mistake as to a partner's identity vitiates consent to sexual activity. See in this connection, $R$ v. Richardson [1999] QB 444 at 447-450; Papadimitropolous v. The Queen (1957) 98 CLR 249 (High Court of Australia) at 260-261; Ormerod, Smith \& Hogan, 632; Simester et.al., Criminal Law, 754-758. When consenting to sexual activity, we usually actively (even if not explicitly) rely on the veracity of our belief as to our sexual partner's identity, thereby making it a precondition for consent. But as Hurd, 'Moral Magic', 127 and Alexander, 'Moral Magic (II)', 167-168 demonstrate, it is possible to imagine cases in which although V is mistaken as to D's identity, the truth of her belief as to D's identity is not a condition of V's consent. In such cases, the mistake is not causative and does not vitiate consent.

47 I use the term 'prima facie consent' to refer to that subset of apparent consent in which the power to consent was 
However, this prima facie consent is undermined when V's autonomy over how to exercise her power to consent was usurped. Hence if $\mathrm{V}$ was forced to allow $\mathrm{D}$ to take her car, she exercises her power over her car by allowing D to take it. This situation is different from one in which D simply steals V's car while V is asleep. However, since V's choice to allow D to take the car was forced, her autonomy over how to exercise her power over her car was usurped, and therefore her consent to D's action is undermined. But does it matter how and through what instrumentality V's autonomy over her power to consent was usurped? What if the background circumstances are such that $\mathrm{V}$ is left with no viable choice but to dispose of $X$ in a particular manner - can she be said to have truly consented to the disposal of $\mathrm{X}$ in that manner? Or is consent only vitiated when $\mathrm{D}$ (the boundary crosser) causes $\mathrm{V}$ to have no viable choice but to dispose of $\mathrm{X}$ in a particular manner? In other words, during the second stage of the inquiry into the occurrence of a presumptive wrong, is the focus on V (“Was V's choice forced?"), or on D (“Did D force V's choice?”)?

Consider the facts of the remarkable case of $R v \cdot$ Cogan \& Leak ${ }^{48}$ in this context. Leak, who had a history of violently assaulting his wife (W), decided to 'punish' her, by having her raped by his friend Cogan. Partly because of Leak's assurances, and partly because of his own intoxication, Cogan believed that $\mathrm{W}$ was consenting to sex when in fact she was not, but had chosen not to resist Cogan out of fear of Leak. Cogan was charged with raping W and Leak with aiding and abetting Cogan to do so. On these facts, W chose to submit to Cogan's crossing of the boundary set by her sexual integrity - she was not forcibly raped. Hence, in order to determine whether this prima facie consent was negated, we need to ascertain whether her entitlement to autonomously dispose of her sexual integrity was usurped. If we conducted this second stage inquiry by reference to the victim W's perspective, we would conclude that a presumptive wrong had occurred. On the other hand, if

actually exercised. This subset includes legally valid consent, as well as apparent consent that is undermined due to mistake, coercion and the like. However it does not include 'consent' apparently granted by infants or an automatons. 48 [1976] QB 217. 
we refer to the perspective of the person who directly ${ }^{49}$ crossed the boundary set by W's sexual integrity, then because Cogan did not usurp W's autonomy to choose how to dispose of her entitlement to sexual integrity, no presumptive wrong would have occurred. When the options are presented this way, it seems clear that the question of whether $\mathrm{W}$ consented cannot depend on whether or not it was Cogan who forced her to submit to sexual intercourse. Surely, W was raped even if Cogan was not (and was not even aware of) the person who held the metaphorical gun to W's head. ${ }^{50}$ This would suggest that our focus, at least when deciding the question of whether a presumptive wrong has occurred, should be on the victim.

This however, does not conclude the issue. The entire purpose of identifying the existence of a presumptive wrong is that once a presumptive wrong has occurred, the person who causes it can be called upon for an explanation for her conduct. Where a boundary set by V's entitlement $\mathrm{X}$ is crossed, we can say that if $\mathrm{V}$ is forced entirely by circumstances to submit to damage to $\mathrm{X}$ also caused by natural causes, then this is not a matter meriting the attention of the criminal law. So if $\mathrm{V}$ is stuck in quicksand and therefore cannot do anything to get her car out of the way of a falling boulder, then she does not suffer a presumptive wrong of the nature relevant to the criminal law.

But consider two variations on these facts. What if:

49 For the present purposes, I am not considering the possibility of treating Cogan as Leak's innocent agent. The analysis would change if we did so, and thereby held Leak responsible for crossing the boundaries set by W's entitlement to sexual integrity.

$50 R$ v. Cogan \& Leak [1976] QB 217 at 223. A contrary view is taken in Andrew P. Simester et.al., Simester and Sullivan's Criminal Law (4th ed., Oxford: Hart, 2010), 246-247. The authors argue that "[r]ape is not an absolute liability crime, constituted simply by its actus reus. The fact that [Cogan] lacked mens rea under the prevailing law at the time meant that, for the purposes of the criminal law (and by contrast with ordinary language), no rape occurred". Even if the authors are correct about whether the prevailing law at the time required this conclusion (and I have my doubts about that), we are fortunately not constrained by the black letter of the law as it stood in October 1974 in England, and can take a more moral intuition driven common-sense view of the facts. 
(a) Under pressure from a villain $\mathrm{Z}, \mathrm{V}$ refrains from moving her car out of the path of the falling boulder; or

(b) Because of her extremely precarious finances (for which no other person is to blame), $\mathrm{V}$ is forced to sell her beloved car (which she would not otherwise have sold at any price) to D for less than its market value.

In case (a), Z does not cross V's primary boundary (which relates to her car) - that boundary crossing is most proximately ascribed to natural causes. However, $\mathrm{Z}$ does cross a boundary set by V's entitlement to decide how to exercise her autonomy over the car. In case (b), D crosses V's primary boundary, but does so with V's prima facie consent. V's decision to exercise her autonomy over the car and sell it to D is entirely due to her circumstances, and cannot be blamed on any person. Is there a presumptive wrong meriting criminal attention in either of these cases?

In case (a), Z obviously commits a presumptive wrong of some description ${ }^{51}$ by crossing the boundary set by V's entitlement to autonomously deal with her car without V's permission. Even if nothing had happened to V's car, Z would have committed the sort of presumptive wrong with which the criminal law is, in principle, concerned, since $\mathrm{Z}$ would have crossed one of V's boundaries without consent. In contrast, case (b) is not a presumptive wrong relevant to criminal law, unless facts are added to this sketch. ${ }^{52}$ Even though V's entitlement to autonomously decide how to deal with her car was in fact constrained, there was no person who could be charged with

51 The description would depend on whether or not D foresaw the damage to V's car. However, even if D did not foresee the resulting damage, D might plausibly be called upon to give an account of her actions in a criminal court.

52 It might make a difference, for instance, that $\mathrm{D}$ had a duty to protect the interests of $\mathrm{V}$, and/or that $\mathrm{D}$ knowingly exploited V's disadvantageous position. Cf. Kirk v. $R$ [2008] EWCA Crim 434 where D was convicted of rape when he had 'consensual' sex with a 13 year old penniless and hungry runaway girl, in exchange for his pocket change. Although this case is sometimes read as laying down the proposition that consent can be vitiated when it is given under circumstantial pressure, I will suggest in §IV.1 that an alternative explanation based on the violation of a duty not to exploit the girl is more apposite. 
wrongfully constraining it. Hence V suffers no wrong meriting the attention of criminal law.

Consider a further variation on case (a). What if, under pressure from Z, V abandons her car. An unconnected third party D then assumes ownership of V's car. Here, V has exercised her power to allow D to cross her primary boundary, but $\mathrm{Z}$ has crossed, without V's permission, the boundary set by V's autonomy over how to deal with the car. ${ }^{53}$ In this case, the criminal law's attention is attracted not by D, but by Z, even though it is D that crosses V's primary boundary. Presumably Z could be charged with crossing the primary boundary through the innocent agency of D.

These examples suggest that at the second stage of the test for a presumptive wrong (which deals with the presence or absence of consent) the focus is indeed upon the victim rather than the person committing the primary boundary crossing, but that apparent consent is only undermined if it is in fact non-existent (due to the apparent consenter's incapacity, or because it is premised on false beliefs as to the nature of the conduct, or the prior or contemporaneous existence of certain circumstances), or if the victim was unfairly pressured by some person (not necessarily the primary boundary crosser) to give prima facie consent. This test establishes only a presumptive wrong, and the question of whether $\mathrm{V}$ consented should be kept separate from the question of whether the primary boundary crosser is guilty. For a defendant to be held criminally liable for the wrong, her mens rea would need to be established, and her defences (if any) would have to fail. When V's consent is vitiated because of pressure applied by an unconnected third party Z, D may well not have committed any prima facie offence if she did not know that V's consent was undermined, and acted within the scope of V's putative consent. Thus Cogan was rightly acquitted of raping Leak's

53 This scenario parallels the facts of Cogan \& Leak but operates in a less charged set of facts. If Leak had forced his wife into prostitution for instance, her submission to sex with the customers would not be consensual even if, in her constrained circumstances, it was her preferred option. Although her customers might have a mens rea based defence to a rape charge, Leak could arguably still be charged with committing rape through their innocent agency. 
wife, not because $\mathrm{W}$ consented, but because Cogan did not have the mens rea to commit rape. ${ }^{54}$

We have shifted the focus of the inquiry into when prima facie consent is undermined away from the primary boundary crossing, and towards the usurpation of V's entitlement to choose whether to consent to the primary boundary crossing. Assuming that V has the capacity to validly consent, and does in fact exercise the power to consent, her prima facie consent to the primary boundary crossing is undermined when V's exercise of autonomy over her primary entitlement is unfairly constrained by some person 'Z'.

\section{The 'Common Framework Proposition'}

How do we demarcate the scope of the possible unfair constraints on the exercise of autonomy? Hurd unconvincingly suggests that we do so by analysing them in parallel with criminal law defences, including both irresponsibility and supervening defences. ${ }^{55}$ A better framework can probably be found outside the criminal law, in the law of contract. For convenience, I will refer to this proposition as the 'Common Frameworks Proposition', or CFP. I suggest the contract law framework because the contract law regime is regularly required to adjudicate on the validity of exercises of autonomous will, and it has developed a jurisprudence that is fairly global, to evaluate the effect of the various constraints that are imposed on autonomous will. In most liberal states, when consent to a contract is induced by fraud, misrepresentation, coercion or undue influence, the contract is voidable. The fact that intuitively this also seems like a plausible list of the unfair constraints on autonomy that undermine consent in the criminal law is not a coincidence - the issue in both areas of law is the undermining of exercises of autonomy, and so the moral instincts applicable in both areas of law are identical. ${ }^{56}$ But although the prima facie case for theorising the

$54 R$ v. Cogan \& Leak [1976] QB 217.

55 Hurd, 'Moral Magic', 139-140.

56 Of course, this assertion is contestable. One plausible line of counter argument is as follows: "The orthodox view is that a contract is a reciprocal exchange of promises, which is an inherently performative act. Consent in the criminal 
undermining of consent in parallel with the undermining of a contract seems plausible, I need to make three caveats, and respond to two immediately apparent difficulties with CFP, at the outset.

The caveats first. Firstly, to the extent that the policy considerations behind the contract law and the criminal law differ, not all rules can be transposed from one context to another. In the discussion that follows, I will flag up some of the instances in which, in my view, different policy considerations require us to apply different rules. However, at this stage it is important to remember that CFP is an argument for identity of approach and not the identity of applicable rules. Secondly, CFP will not generate a description of the content of the rules that operate within the framework. Therefore while CFP will suggest that coercive pressure should be understood to undermine prima facie consent in the same way in contract and criminal law, it will not itself explain the minutiae of the distinction between legitimate pressure and illegitimate or coercive pressure. Thirdly, it is apparent that different evaluative standards are referred to in deciding whether consent was vitiated for the purposes of civil law and for the purposes of criminal law. In fact, different standards apply even within the criminal law, such that consent granted under a given set of conditions may effectively protect a defendant against a conviction for one offence but not for another. Thus the law may deem a person too intoxicated to consent to sex, but not too intoxicated to consent to a

law is not (or at least, is not obviously) based on such a promise. Therefore, the factors that undermine a promise for contract law may well be different from the factors that undermine the (possibly) more subjective exercise of autonomy involved in granting consent". I cannot mount a full rebuttal of such an argument here, but briefly stated, my response is as follows: Firstly, whether or not contracts are built on reciprocal promises, it remains true that any complete account of contractual obligation must include copious reference to obligations created through the exercise of autonomy. See in this connection Lon L. Fuller, "Consideration and Form", Columbia Law Review 41 (1941) 799, 806-823. Since my focus is on the underlying exercise of autonomy rather than the forms in which it manifests, it remains fair to expect some correspondence between the factors that undermine autonomy in both contract law, and criminal law. Secondly, I do not expect an exact correspondence. As will become clear in the discussion that follows, I recognise that on some issues, the different considerations relevant to contract law and the criminal law will mean that different approaches will be necessarily. 
handshake or to another person using her bathroom. This idea has been explored in depth by Burra who notes the domain-specific nature of the factors that make non-consensual behaviour wrong. ${ }^{57}$ This does not however mean that in respect of factors that defeat them, consent in civil and criminal law cannot share the same framework, while referring to different standards. The third caveat therefore, is that CFP is a proposition about frameworks and not about the standards that they incorporate. We turn now to the apparent difficulties with CFP.

For one, contracts induced by unfair constraints on autonomy are not void - they are voidable. In the criminal law, we would probably want to say that consent induced by coercion is void rather than merely voidable. This however, is not a major problem. The civil law notion of voidable contract recognises that a prima facie valid contract has actually been made. Competent parties have reached a meeting of minds on the same thing in the same sense. However, we allow the party that contracted while under the influence of unfair constraints on her autonomy the option of either performing the contract, or avoiding it. In like fashion, when V, being competent to do so, actually exercises her autonomy to permit D to cross the boundary set by her primary entitlement X, this is prima facie a valid exercise of autonomy. Nevertheless when V's exercise of autonomy over $\mathrm{X}$ was unfairly constrained, we recognise that the prima facie consent is blemished. The only difference between the position in contract law and in criminal law is that in contract law, by legal fiction, we create for the constrained party the option of treating the contract as valid, whereas in criminal law, we do not. This difference is a matter of (civil law) policy, and does not undermine the in-principle correspondence between the contract law rules and rules of consent.

A second possible area of stress is that there exist factors other than the unfair constraints on autonomy enumerated, that also affect the validity of contracts. Consider for instance, infancy, insanity and mistakes. ${ }^{58}$ How do these factors fit into the proposed analogy? But, here too we find

57 Burra, 'Significance', 11.

58 As will be obvious from the caveats made at the beginning of this section, we can set aside cases in which contracts 
that the correspondence between contract law and criminal law holds up to scrutiny tolerably. Insanity and infancy go to the capacity to exercise the autonomy necessary both to contract and to consent. Mistakes however, require special consideration. In contract law, generally it is only mistakes about fundamental contractual terms, like the identity of the subject matter of the contract, that are treated as vitiating the contract. Incidental mistakes such as mistakes about the value of goods or services tend not to vitiate contracts. However, I have argued in $\S I I I .1$ above, that V's consent is undermined by all mistakes as to the nature of the conduct to which consent is given, and all mistakes as to the existence of circumstances, the existence of which were, by an exercise of volition, made preconditions for her consent. Although contract law and the criminal law seem to reach different conclusions, the difference stems from the different policy considerations that apply. The vitiation of a contract has automatic consequences for both, the party acting under the mistaken belief, and the counter-party, whose behaviour may have been entirely unimpeachable. As a policy matter therefore, the contract law protects the counter-party ${ }^{59}$ by limiting the types of mistakes that vitiate a contract. The undermining of consent in criminal law, does not automatically condemn the boundary crosser to criminal liability. She may still be able to raise a mens rea based defence. As such there is no need to artificially narrow the reach of V's powers of autonomy.

These arguments merely dispel some of the obvious objections to CFP. However, the positive case for supporting CFP is best made by demonstrating that it can suggest coherent principles to explain the intuitions that manifest in consent-related criminal law decisions that are not satisfactorily explained by reference to existing criminal law doctrine. I will attempt such a

are treated as being void because they run contrary to public policy. Public policy influenced rules exist in relation to the validity of consent in the criminal law as well, but since different policy considerations apply in different contexts, the rules are not likely to be directly comparable.

59 As Randy E. Barnett, “A Consent Theory of Contract”, Columbia Law Review 86 (1986) 269, 272-273, 306-307, explains, contract law does not rely solely on a promiser's subjective intent to determine the scope of her promise, because to do so would unfairly prejudice the counter-party. 
demonstration in respect of two areas of doctrinal uncertainty in the English criminal law.

\section{IV.1 Criminal law consent and contract law principles of undue influence}

Although the concept is entrenched in contract law, the English criminal courts have rarely applied the principles of undue influence to the analysis of consent other than in the context of property offences, ${ }^{60}$ even though there have been several opportunities to do so, particularly in the context of sexual offences. ${ }^{61}$ I will examine two cases that the English Court of Appeal did not analyse in terms of undue influence, and show that much greater doctrinal clarity could have been achieved by using the language of undue influence (which would have been consistent with CFP).

First, consider the case of Kirk v. $R \cdot{ }^{62} \mathrm{D}$ was convicted of rape when he had 'consensual' sex with a 13 year old penniless and hungry runaway girl, in exchange for his pocket change. $\mathrm{D}$ was the brother of the child's uncle, and was alleged, along with the uncle, to have repeatedly sexually abused her even previously. Because English criminal theory does not adequately acknowledge undue influence (as understood in contract law) as a factor that can vitiate consent, this case is sometimes taken as laying down the proposition that consent can be vitiated when it is given due to circumstantial pressures. ${ }^{63}$ Such a reading challenges the proposition made $§ I I I .2$ that where a

60 See for instance $R$ v. Hinks [2001] 2 AC 241; Re Beaney [1978] 1 WLR 770.

61 Interestingly, Hurd's theory that we understand prima facie consent to be vitiated for the same reasons that we understand prima facie criminal responsibility to be excused would support extant English case law. A defendant is excused of criminal liability only if she can establish a very specific form of undue influence - coercion. Looser notions of undue influence such as abuse of trust and exploitation do not seem to be enough. If it can be shown that undue influence has a role in explaining our intuitions in cases in which we agree that consent is vitiated, then this suggests not only that extant doctrinal law has missed a trick, but also that Hurd's second identity thesis is wrong.

62 [2008] EWCA Crim 434.

63 See for instance Shlomit Wallerstein, “'A drunken consent is still consent' - or is it? A critical analysis of the law on a drunken consent to sex following Bree", Journal of Criminal Law 73(4) (2009) 318, 333; Jo Miles, "Sexual offences: consent, capacity and children", Archbold News 10 (2008) 6, 8. 
person's autonomy in exercising her power to consent is constrained solely by circumstances, her consent is not necessarily vitiated by any unfair constraint on her autonomy. However, as a normative proposition, it seems far from convincing. It leads to counterintuitive results in cases such as the hypothetical case discussed in $§$ III. $2 ;{ }^{64}$ and it does not provide much guidance as to how serious the circumstances must be before they vitiate consent, or whether D should know or is required to inquire about those circumstances. Furthermore, it does not explain why an autonomous individual D, should be required to look out for V's interests when relying on her consent, but not in general. ${ }^{65}$ The court's judgment itself is not explicit on the reasoning adopted, but the trial judge summarised the prosecution's case thus:

...the defendant took advantage of a hungry and vulnerable child whom he knew had been abused by his brother and to a lesser extent by himself, which means that she was submitting because her will was overcome through hunger, and I will use the word desperation again, and that say the prosecution is not true consent. ${ }^{66}$

One has considerable intuitive sympathy for the outcome in Kirk, and in fact the court did probably reach the correct conclusion. However, its conclusion is best explained not on the basis that the circumstantial pressures bearing on the victim vitiated her consent but rather, on a basis drawn from the law of contract. It is fairly well accepted that if consent to a contract was caused by undue influence, then the contract is voidable at the option of the party whose consent was so caused. For an outline of this challenge to a contract, I refer to the Indian Contract Act, 1872, which was drafted by the British and which contains a very accessible summary of the core common law principles relating to undue influence. Where one party (A) is in a position to dominate the will of another (B) and uses that position to obtain an unfair advantage over B, A uses undue influence to

64 In which V was compelled by her (self-inflicted) financial troubles to sell her beloved car to an unrelated person D.

65 For instance, the English criminal law does not impose upon D a duty to rescue V from peril even when such rescue could easily have been effected.

66 Kirk v. $R$ [2008] EWCA Crim 434. 
form the contract. A is deemed to be in a position to dominate the will of B where A holds a position of real or apparent authority over B, or stands in a fiduciary relationship to B, or when B's mental capacity is permanently or temporarily affected by reason of age, or mental or bodily distress. Where $\mathrm{A}$ is in a position to dominate the will of B and the contract appears unfair, $\mathrm{A}$ is rebuttably presumed to have used her position to obtain an unfair advantage. ${ }^{67}$

The same approach, if applied to the criminal law would easily explain the decision in Kirk and in fact, the prosecution did implicitly rely on the fact that the defendant was in a position to dominate the will of the victim because (a) the victim was a hungry, vulnerable and desperate child; (b) the defendant had previously abused her; and (c) the defendant was an adult member of her extended family. Moreover, the defendant knew all of these facts. In such circumstances, it is clear that the defendant was in a position to dominate the will of the child, and the one-sidedness of the 'transaction' that ensued made it apparent that the consent granted was obtained by the exercise of undue influence. Thus inevitably, the consent would be vitiated, and a conviction for rape would result. This analysis provides a better explanation of why we intuitively think it was wrong to treat the child as having actually consented. Even if the defendant had somehow not known of the facts that establish that the child's will was dominated - say if he had been an automaton at the time of acting - we could still plausibly say that the child had not validly consented although we might grant that the defendant would have a mens rea based defence available to him (in addition to the obvious irresponsibility defence). This analysis of the manner in which consent can be said to have been vitiated accounts for our intuitions as to the validity of V's consent without unduly extending the scope of factors that might potentially vitiate consent, or distorting central features of the criminal law by imposing upon people onerous duties to investigate the factors that motivated any

67 Ss.16 and 19A, Indian Contract Act, 1872. For a more modern summary of the English Law of undue influence see Jack Beatson et.al., Anson's Law of Contract (Oxford: Oxford University Press, 2010) 359-367; Graham Virgo, The Principles of the Law of Restitution (Oxford: Oxford University Press, 2005), 244-260. 
instance of prima facie consent. Interestingly, modern English law relating to sexual offences also unequivocally adopts a similar, though perhaps overly heavy-handed, approach in relation to its abuse of trust offences, ${ }^{68}$ inasmuch as it treats as invalid any consent to sexual activity given within the context of relationships in which it is likely that D dominates V's will.

Consider also the case of $R v$. Jheeta, ${ }^{69}$ where in order to prevent his girlfriend (V), from ending their sexual relationship, for four years D assumed the identities of different fictional police officers, and sent $\mathrm{V}$ text messages telling her that $\mathrm{D}$ was suicidal, that he would kill himself if she stopped having sex with him, and that she should have sex with him, failing which she would be fined. V therefore reluctantly 'consented' to sex with D on several occasions. When the truth came out, D was convicted of rape although the court found that $\mathrm{D}$ had not deceived $\mathrm{V}$ as to the nature and purpose of the sexual act involved. D's conviction was sustained on the basis of his admission that in view of his deception he thought that there were occasions on which D and V had sex though V wasn't 'truly consenting', and that his deception had led V to have sex with him more frequently than she would otherwise have done. This was a rather shaky basis on which to uphold the conviction, because it relied on D's admissions based on his common-sense conception of consent, to convict D for acting in the absence of (the criminal law's established conception of) consent. By this stage in the study it must at least be clear that the equivalence of these two conceptions of consent cannot be taken for granted. Recognising this, some commentators have suggested that Jheeta too can be analysed as a case in which circumstantial pressure vitiated consent. ${ }^{70}$

In Jheeta too, the outcome reached was probably correct, and again, there is no need to suppose that our intuitions in relation to those facts can only be explained if we accept that circumstances can vitiate consent. The framework of undue influence in the contract law explains

68 Ss. 16 to 24, English Sexual Offences Act, 2003.

69 [2007] EWCA Crim 1699.

70 Miles, 'Sexual Offences', 7-8. 
why. In Jheeta, D had assumed a position of apparent authority over V, and therefore he was in a position to dominate her will. He admitted to having obtained an unfair advantage by the use of this position, and therefore, V's consent could straightforwardly be attributed to D's exercise of undue influence over V. Her consent would therefore be vitiated and D's conviction would follow. ${ }^{71}$

\section{IV.2 Coercion and consent - the legitimacy of pressure as the crucial factor}

For a second demonstration of the value of CFP, we may look to an area of doctrinal uncertainty relating to how coercion vitiates consent in the criminal law. In $R v$. Olugboja $^{72}$ the English Court of Appeals held that all the various attitudes of interest to the criminal law (it used the term 'mental states') that V could have towards D's boundary crossing, lie on a single spectrum. These attitudes include actual desire, reluctant acquiescence, and mere submission. According to the court, the criminal law draws a line along this spectrum between reluctant acquiescence (which, along with all more positive attitudes towards the boundary crossing, amounts to valid consent) and mere submission (which, along with more negative attitudes towards the boundary crossing, does not). ${ }^{73}$ The court was less than clear in identifying the variable that defines this spectrum, but held that the trial judge's characterisation of it as a function of the 'constraints operating on [V's] will' was not a

71 The same reasoning would also explain the decision in a case recounted in $R v$. Wellard (1978) $67 \mathrm{Cr}$ App $\mathrm{R} 364$ at 368. Here D found V and her boyfriend kissing in "an area frequented by courting couples". He pretended to be a police officer, and after sending V's boyfriend away, made V 'consent' to sex with him by threatening to report her behaviour to her parents and to file an official report. D was convicted of rape. But c.f. the decision in the unreported case of $R v$. Kirby, mentioned in news items in "The Times" on $19^{\text {th }}$ December 1961, in which on very similar facts D was found to have no case to answer. The only difference in Kirby was that D was actually a police constable. I think that decision is probably indefensible.

72 [1982] QB 320. Here V submitted to intercourse with D after she had been taken to D's friend's bungalow and raped by D's friend. D made no explicit threat but ordered her to submit to intercourse. V was held not to have consented.

73 Id. at 331-332. See also Simon Gardner, “Appreciating Olugboja”, Legal Studies 16 (1996) 275, 277-279. 
misdirection because the trial judge had always linked the word 'constraint' with the word 'fear'. ${ }^{74}$ Since it had already held that there was no need to show that V was put in fear of violence ${ }^{75}$ the court must have been referring to a more general fear of unpleasant consequences. For instance, the court thought that in principle, and depending on V's circumstances, it was possible that her fear of losing a role in a film, or the disclosure of embarrassing information, could vitiate her consent. ${ }^{76}$ For the court therefore, the difference between actual desire, reluctant acquiescence, and mere submission, was simply the amount of pressure brought to bear on V. Accordingly, it held that juries should be asked to locate the line on the spectrum between mere submission and reluctant acquiescence by "applying their combined good sense, experience and knowledge of human nature and modern behaviour". ${ }^{77}$ This line of thinking supports the view that prima facie consent can be vitiated even when the person presenting $\mathrm{V}$ with her options is not responsible for causing the unwelcome consequences that would ensue if $\mathrm{V}$ refused to submit to the boundary crossing, and even if V's lot was actually improved by having some alternative to these unwelcome consequences. Consider the facts of Latter v. Bradell, where V, a Victorian domestic servant, having no legal right to further employment, but was offered it on the condition that she consent to an intimate examination to ascertain whether she was pregnant. She submitted, but later sued for assault. ${ }^{78}$ Some commentators, following the Olugboja line, argue that since V's employment opportunities were likely to be extremely limited, her baseline situation was so poor that even presenting her with the opportunity to improve it by submitting to the examination was arguably coercive. ${ }^{79}$ The

74 R. Olugboja [1982] QB 320 at 327, 332.

$75 I d$. at 331 .

76 Id. at 328,332 .

77 Id. at 332 .

78 (1881) 50 LJQB 166. V was held to have consented on these facts.

79 Simester et.al., Criminal Law, 753. Our intuitive sympathy for the maid's predicament may be attributable to the fact that given her vulnerable position, we might quite plausibly feel that she was subjected to undue influence, and 
Olugboja direction on advising juries has been since been approved and cited repeatedly. ${ }^{80}$

In Olugboja, the courts saw no need to distinguish between legitimate pressure and illegitimate pressure, requiring only sufficient pressure to render $\mathrm{V}$ non-autonomous. However, many academicians argue that when $\mathrm{V}$ accords prima facie consent to a boundary crossing because D has presented her with the option of either consenting or suffering an unpleasant consequence, the validity of V's prima facie consent depends on whether D's proposal is a threat or an offer. A threat imposes illegitimate pressure, in that it illegitimately narrows V's options for maintaining or improving her baseline state, and therefore vitiates consent. By contrast, an offer expands V's options for maintaining or improving her baseline state, and so no matter how distasteful it may be, it does not impose illegitimate pressure or vitiate consent, ${ }^{81}$ even in cases like Latter v. Braddell. Which approach is more convincing? For clues, we can look to contract law.

In contract law, when $\mathrm{V}$ agrees to terms because of pressure, the contract is voidable if the pressure was illegitimate. ${ }^{82}$ The distinction between legitimate and illegitimate pressure in contract stems from the same principles as the distinction the aforementioned criminal law academicians make between threats and offers in their proposals as to the criminal law of consent. Hence,

...The crux of the distinction between threats [illegitimate pressure] and offers [legitimate pressure] lies in the fact that 'A threatens B by proposing to make B worse off relative to some baseline; A makes an offer to B by proposing to make B better off relative to some baseline'; offers augment a

therefore, her consent was vitiated. For the present purposes however, we should ignore that possibility and intuitive pull arising from it. See also Ormerod, Smith \& Hogan, 634, 720-721.

80 See $R$ v. Robinson [2011] EWCA Crim 916; $R$ v. Bree [2008] QB 131; $R$ v. Malone [1998] 2 Cr App R 447.

81 Alexander, 'Moral Magic (II)', 168-170; Hurd, 'Moral Magic', 144-145; Simester et.al., Criminal Law, 753. See also Alexander's model of how coercion defeats consent, described in §III above.

82 Barton v. Armstrong [1976] AC 104 at 118-120, 121; Universe Tankships Inc of Monrovia v International Transport Workers Federation [1983] 1 AC 366 at 400; H.G. Beale et.al. (Eds.), Chitty on Contracts Vol. I General Principles (London: Sweet \& Maxwell, 2012) 674; Beatson et.al., Anson's Contract, 350-351; Virgo, Restitution, $191-195$. 
party's alternatives, whereas threats reduce them. ${ }^{83}$

Broadly speaking, a person's baseline state includes her circumstances and all the claims she has against others, including the claim that they not act unlawfully vis-a-vis her. ${ }^{84}$ Hence, if D makes a proposal that is itself unlawful (blackmail), or threatens to commit an unlawful act if $\mathrm{V}$ refuses to contract, D applies illegitimate pressure. If such pressure causes V to contract, V's consent is vitiated, and the contract is treated as voidable.

This approach, if replicated in the criminal law, would maintain D's conviction in Olugboja - D's trial court conviction showed that the jury had found that V had acted out of fear of D's implicit threat that he would cause some unspecified but unlawful adverse consequences if she did not submit. D had therefore illegitimately pressured V, and insofar as this pressure was causative of V's prima facie consent, V would not have been found to have validly consented to intercourse.

If the contract law position is convincing, this suggests that the court in Olugboja may have misidentified the manner in which pressure vitiates consent in the criminal law. It does seem anomalous to suggest, along with the court in Olugboja, that the difference between consent and non-consent is simply a function of the amount of pressure operating on V. Almost all of life's decisions are made under some sort of pressure, whether circumstantial, or applied by other persons. There is no general prohibition on $\mathrm{D}$ pressuring $\mathrm{V}$ by coaxing or cajoling her. In fact, most people would agree that $\mathrm{D}$ does not rape $\mathrm{V}$ when he suggests that he might break off their relationship if she does not consent to sex. But if some forms of pressure may legitimately be used, then it is illogical to argue that the distinction between consent and non-consent depends solely on

83 See also Rick Bigwood, “Coercion in Contract: The Theoretical Constructs of Duress”, The University of Toronto Law Journal 46(2) (1996) 201, 212. See also Alan Wertheimer, Coercion (Princeton: Princeton University Press, 1987) 204-208.

84 Bigwood, 'Coercion in Contract', 212-214. See also Wertheimer, Coercion, 206. Admittedly this is a simplification of the position in contract, but it suffices for the present purposes. 
the amount of pressure exerted on V. It may well be possible to exert far more pressure on V using legitimate commercial bargaining power, than by illegitimate threats of minor vandalism. Even arguing that the distinction depends partly on the amount of pressure exerted on V seems difficult: given that the criminal law does not generally require one to look out for the interests of others, why should D not be permitted to exert all legitimate pressure he can on V, and instead be restricted only to using moderate pressure? Finally, the contract law approach allows for guidance that is far more precise and easy to apply than the Olugboja guidance. All of this suggests that even in the criminal law, juries considering the effect of causative pressure on prima facie consent ought to be advised in terms of legitimate and illegitimate pressure, ${ }^{85}$ instead of unhelpfully asking them to apply their combined good sense, experience and knowledge of human nature and modern behaviour.

\section{IV.3 Fraud and misrepresentation - a reminder of the limits of CFP}

These demonstrations of the utility of CFP make a plausible positive case in support of CFP, but it is important not to lose sight of CFP's limitations. I have already mentioned that where the policy objectives of contract law and the criminal law differ, the correspondence between the analytical frameworks they ought to employ will break down. A stark illustration of this is the nontransferability of the contract law's approach to the effect of fraud and misrepresentation on consent to the criminal law. As pointed out in $\S$ III.1, in contract law, the voiding of a contract necessarily affects all parties to it. Hence, when one party contracts on the basis of an incorrect belief, a policy concern for the interests of the counter-party means that the law stops short of declaring that the contract is automatically void or voidable. Therefore, a contract is only undermined by causative mistakes about beliefs or terms identified as usually being fundamental to contract, and causative

85 Interestingly, English statutory law also suggests that the distinction between legitimate and illegitimate pressure has a place in the criminal law. S.75(1) read with Ss. 75(2)(a), (b) and (c) of the English Sexual Offences Act, 2003 identifies some forms of pressure (threats of violence, and unlawful detention) that give rise to a presumption of non-consent. These forms of pressure are therefore treated as being at least presumptively illegitimate. 
mistakes induced by a counter-party, either by fraud or misrepresentation.

None of these considerations is relevant to the criminal law, because when V's consent is predicated on the truth of certain beliefs as to circumstances, making a declaration that her consent is non est because of the falsehood of these beliefs does not automatically result in criminal liability for D. D may still raise a mens rea based defence. This is why it is well established that for the purposes of the criminal law, fraud played on $\mathrm{V}$ does not necessarily negative her consent. ${ }^{86}$ As the court in Richardson explained, "[t]he common law is not concerned with the question whether the mistaken consent has been induced by fraud on the part of the accused or has been self induced. It is the nature of the mistake that is relevant, and not the reason why the mistake has been made". ${ }^{87} \mathrm{~A}$ normative model of how mistakes affect consent has been described in $\S I I I .1$, and since it addresses all mistakes, however caused, there is no need for special rules addressing the effect of fraud or misrepresentation on consent in the criminal law.

CFP is a tentative proposition, and much more needs to be done to develop it, although I cannot undertake that task here. However if proved, this thesis has a significant pay-off. A proved correspondence between the contract law and criminal law rules of consent would allow us to refer to the well developed contract law jurisprudence to develop answers to many questions relating to when prima facie consent is undermined.

\section{Conclusion}

Where the law permits consent to validate a boundary crossing, there is value in segregating the two

86 R v. Richardson [1999] QB 444 at 447-450; Papadimitropolous v. The Queen (1957) 98 CLR 249 (High Court of Australia) at 260-261; $R$ v. Clarence (1888) 22 QBD 23 at 27, 44 (overruled on the slightly different issue of whether consent to intercourse automatically includes consent to the risk of infection); David Ormerod, Smith and Hogan's Criminal Law (Oxford: Oxford University Press, 2011) 632;

$87 R$ v. Richardson [1999] QB 444 at 450. See also to the same effect Papadimitropolous v. The Queen (1957) 98 CLR 249 (High Court of Australia) at 260-261. 
questions involved in determining whether legally valid consent has been given, viz.

1. Did V exercise her power to consent? If so,

2. Was V's choice to exercise that power sufficiently autonomous to be effective?

As has been argued, these questions are answered by reference to different tests and considerations. Moreover, particularly in the context of the second question the criminal law can learn a lot by looking outside the bounds of its own discipline. It has long been recognised that the concept of consent has importance both in civil and criminal law. Theorists also seem to agree that consent's morally transformative character stems from it being an expression of moral autonomy. Since moral autonomy is not a feature unique to either the criminal law or the civil law, and since it grounds consent in both, it seems almost trite to suggest that there would be deep and abiding links between the way in which consent operates in the civil and the criminal law. Yet courts and theorists have rarely made enough of the common roots of consent in different areas of law. Of the multitude of consent related issues in the criminal law, I picked out just a few test cases to highlight these links. Of the various branches of civil law, I picked out just the contract law as a source of instruction for the criminal law. Even the very limited study that resulted suggests that the criminal law of consent can benefit greatly from referring to civil law frameworks. It seems likely that much more value can be gleaned by the criminal law of consent through considering the frameworks relating to consent developed by the civil law, including, but not necessarily limited to the law of contract. 